\title{
Evaluation of Acceptability, Safety, Efficacy and Outcome of Postplacental IUCD Insertion in Women Undergoing both Vaginal Delivery and Caesarean Section- A Cohort Study
}

SHIBRAM CHATTOPADHYAY ${ }^{1}$, SUBIR KUMAR BHATTACHARYYA ${ }^{2}$,

\section{ABSTRACT}

Introduction: Prevention of unplanned and unwanted pregnancies could help avert $20-35 \%$ of maternal deaths and as many as $20 \%$ of infant death. Despite many advantages of, mothers of India are reluctant for IUCD use.

Aim: To determine the acceptability, safety, efficacy and outcome of Postpartum Intrauterine Contraceptive Device (PPIUCD) following both vaginal delivery and caesarean section.

Materials and Methods: A descriptive prospective cohort study conducted in the Department of Obstetrics and Gynaecology in a tertiary care institute in Eastern India from August 2019 to July 2020. Among the women delivered almost all mothers were counseled about postplacental IUCD insertion and the first 100 mother who satisfy inclusion criteria were incorporated in the present study. Out of 100 mothers, six mother refused and 94 mothers accepted PPIUCD. Only three mothers were lost to follow-up. Ninety-one mothers were followed-up in postnatal clinic after 6 weeks, 12 weeks, 24 weeks and 48 weeks. Primary parameter was to assess acceptance rate and reason for acceptance. Secondary variables were refusal rate and reason for refusal, reason for removal, failure rate and complications. Collected data were then analysed by SPSS (version 27.0; SPSS Inc., Chicago, IL, USA) and GraphPad Prism version 5.

Results: Majority of mothers were in the 21-25 years age group and completed secondary school education. A very high rate of acceptance of about $94 \%$ was found. The most common reason for acceptance was its long-term effect of contraception (40.4\%) followed by reversible nature $(27.7 \%)$. This study showed that refusal rate was $6 \%$, majority due to fear of complications. Among 91 mothers followed-up for safety profile of PPIUCD, majority $(81.3 \%)$ had no complication which was statistically significant $(p<0.0001)$. Out of 91 women, 80 mothers $(87.9 \%)$ continued PPIUCD, three mothers had abdominal discomfort, 10 had abnormal bleeding P/V, and 67 mothers (90.4\%) had no complications and failure rate was $2.2 \%$. Only two mothers conceived with PPIUCD in-situ. Expulsion rate was 4.4\%. Out of 91 mothers followed-up, only four had expulsion.

Conclusion: PPIUCD is widely accepted, efficacious, safe method of family planning, that can reduce maternal morbidity and mortality.

\section{INTRODUCTION}

Insertion of IUCD in immediate postpartum period is an effective, safe, and convenient contraceptive intervention in both cesarean and vaginal deliveries [1]. India launched the national family welfare programme in 1951. Over the years India's family planning programme has evolved with the shift in focus from merely population control to more critical issues of saving the lives and improving the health of mothers and newborns [2]. Use of reversible or spacing methods of contraceptives can save women's lives and health due to a reduction in unwanted, closely spaced and mistimed pregnancies and thus avoiding pregnancies with higher risks and chances of abortions, many of which may be unsafe [2]

Approximately, $61 \%$ of births in India occur within 36 months of previous births. This means the birth to pregnancy intervals in $61 \%$ of births are shorter than the recommended birth to pregnancy interval [2]. Immediate postpartum Cu-IUD insertion, particularly when insertion occurs immediately after delivery of the placenta, is associated with lower expulsion rates than delayed postpartum insertion. Additionally, postplacental placement at the time of caesarean section has lower expulsion rates than postplacental vaginal insertions [3]. In India knowledge of awareness of contraceptive methods is inadequate and many misconceptions are present in the society [4].
Thus, importance of spacing between childbirths with the use of PPIUCD can be considered. Taking advantage of the immediate postplacental period for counseling on family planning, PPIUCD is a good option as a contraceptive method. In low-resource countries, delivery is probably the only time when a healthy woman comes into contact with a healthcare provider and the likelihood of her returning for contraceptive advice is low [5]. The postpartum period is potentially an ideal time to begin contraception as women are more strongly motivated to do so at this time, which also has the advantage of being convenient for both patients and healthcare providers [6]. This is particularly important for women who have limited access to medical care.

Many women also find the IUCD to be very convenient, because it requires little attention once it is inserted. Increasing numbers of women in India are having their babies born in hospitals after introduction of Janani Suraksha Yojana (JSY) and Janani Shishu Suraksha Yojna (JSSY). It allows opportunity for the state to provide PPIUCD in a big way. Despite of IUCD being a costeffective, long acting, safe, reversible, coital independent method for contraception, mothers in India are reluctant for IUCD use. Due to lack of awareness and myths prevailing for IUCD, present rate of IUCD use in India is $2 \%$, which is way lesser than required [5]. It is still relatively unknown why acceptance of IUCD among women both urban and rural is low. This can be due to various reasons i.e., 
medical or social. Current Indian medical literature does not reflect clearly on this aspect. Thus, this present study was conducted to determine the acceptability, safety, efficacy and outcome of PPIUCD following both vaginal delivery and caesarean section.

\section{MATERIALS AND METHODS}

This was a descriptive prospective cohort study conducted in the Department of Obstetrics and Gynaecology, Nil Ratan Sircar Medical College and Hospital, Kolkata, a tertiary care institution in Eastern India. It was performed between the time period of one year from August 2019 to July 2020. A prior approval for the protocol of the study was obtained from the Institutional Ethics Committee (No/ NMC/10084 dated 03/01/2019) and each participant was enrolled after proper informed consent in their vernacular language.

Inclusion criteria: Women with singleton or multiple pregnancy, age between 19 to 35 years, delivering at 36-40 weeks of gestation irrespective of baby outcome, not willing for permanent sterilisation, delivering by vaginal or caesarean section, haemoglobin level more than $9 \mathrm{gm} \%$ and mothers willing to participate were included in this study.

Exclusion criteria: Women having history of rupture of membranes $>12$ hours, fever in the last trimester, heart disease, antepartum haemorrhage, lower genital tract infections, mothers with anaemia, postpartum haemorrhage complicating deliveries, manual removal of placenta with previous allergic reaction to IUCD, anomalous uterus as evidenced in early scans, not willing for IUCD insertion were excluded from our study.

Sample size calculation: A previous study [6] showed that acceptance rate was 37.4\%. Sample size was calculated using OpenEpi, Version 3, open source calculator-SSPropor by taking 95\% confidence interval. It was found to be 87 . After adding $10 \%$ drop out, total of 100 women were taken for this study.

\section{Study Procedure}

Among the women delivered at our institution, almost all mothers were counseled about postplacental IUCD insertion in antenatal period and the first 100 mother who satisfy inclusion criteria were incorporated in our study. Out of 100 mothers, six mothers refused and 94 mothers accepted PPIUCD [Table/Fig-1]. All women had postplacental insertion of IUCD under sterile conditions and antibiotic coverage to ensure asepsis in the mother. Primary parameter was to assess acceptance rate and reason for acceptance. Secondary variables were refusal rate and reason for refusal, reason for removal, failure rate and complications. Informed written consent was taken from the mother before insertion after elaborating the

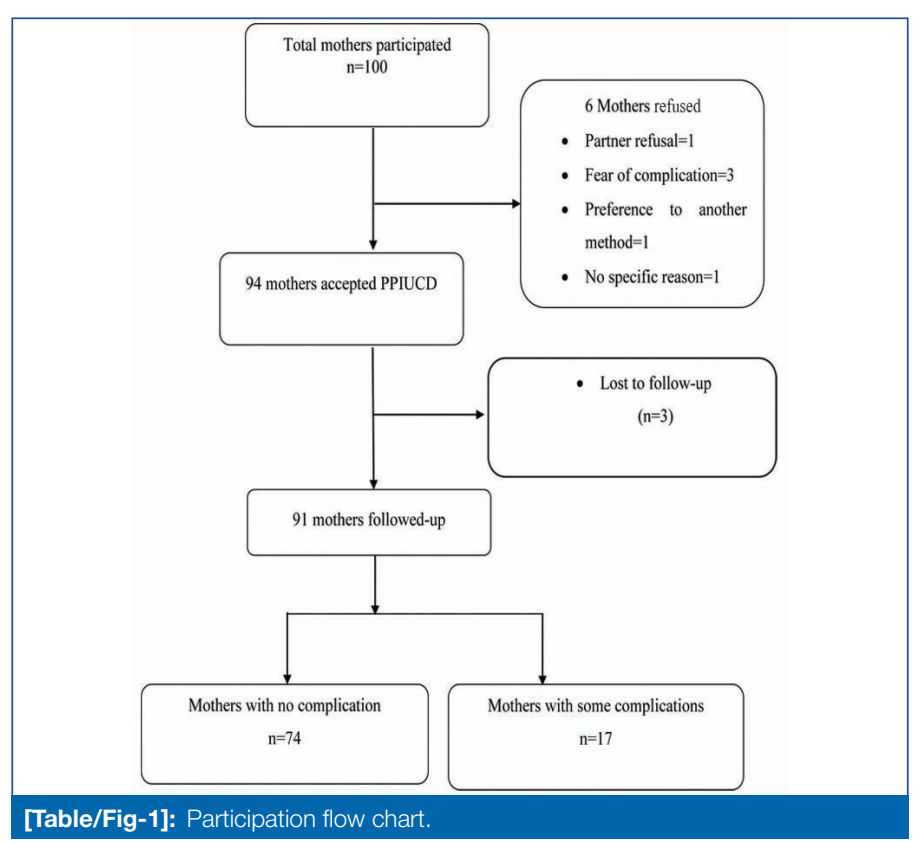

possible complaints following insertion and reassurance. After taking consent, a Cu-T 380A was inserted using Kelly's Forceps by doctors only within 10 minutes of placental expulsion in vaginal deliveries. IUCD was held suitably with the instrument and was inserted up to the fundus of the uterus and the IUCD was released. Intraoperative insertion at cesarean delivery was done by holding the IUCD between the middle and index fingers of the hand and passed it through the uterine incision. After placing it at the fundus of the uterus, the hand was withdrawn taking care that the IUCD remains properly placed.

All mothers were advised to attend postnatal clinic after 6 weeks, 12 weeks, 24 weeks and 48 weeks for follow-up, and presence of $\mathrm{Cu}$-T were verified, patients were treated symptomatically and reassured about the safety of $\mathrm{Cu}-\mathrm{T}$. Mothers who did not come for follow-up were telephoned to the number provided during admission for follow-up examination at OPD. Complications (e.g., expulsion, missing thread) were recorded at return visits. Only three mothers were lost to follow-up.

\section{STATISTICAL ANALYSIS}

Data was entered into a Microsoft excel spreadsheet and then analysed by SPSS (version 27.0; SPSS Inc., Chicago, IL, USA) and GraphPad Prism version 5. Data had been summarised as mean and standard deviation for numerical variables and count and percentages for categorical variables. Two-sample t-tests for a difference in mean involved independent samples or unpaired samples. Unpaired proportions were compared by Chi-square test or Fischer's-exact test, as appropriate. Z-test (Standard Normal Deviate) was used to test the significant difference of proportions. Once a t value was determined, a p-value was found using a table of values from Student's t distribution. $p$-value $\leq 0.05$ was considered for statistically significant.

\section{RESULTS}

During the study period, among the women delivered at the institution, almost all mothers were counselled about postplacental IUCD insertion in antenatal period and the first 100 women who were willing were incorporated. Out of 100 mothers, six mothers refused and three mothers were lost to follow-up. A total of 91 women were followed-up. [Table/Fig-2] showed that the majority of mothers who made an informed choice for PPIUD insertion were in the 21-25 years age group. About 47\% women who accepted PPIUCD, were primipara mother which was statistically significant

\begin{tabular}{|c|c|c|c|}
\hline Characteristics & Numbers & Percentages (\%) & $\mathrm{p}$-value \\
\hline \multicolumn{4}{|l|}{ Age (years) ${ }^{\star}$} \\
\hline$\leq 20$ & 14 & 14 & \multirow{5}{*}{0.77182} \\
\hline $21-25$ & 41 & 41 & \\
\hline $26-30$ & 39 & 39 & \\
\hline$>30$ & 6 & 6 & \\
\hline Total & 100 & 100 & \\
\hline \multicolumn{4}{|l|}{ Parity $^{\dagger}$} \\
\hline $\mathrm{PO}+0$ & 17 & 17 & \multirow{7}{*}{0.03} \\
\hline $\mathrm{P} 0+1$ & 30 & 30 & \\
\hline $\mathrm{P} 1+0$ & 14 & 14 & \\
\hline $\mathrm{P} 1+1$ & 11 & 11 & \\
\hline $\mathrm{P} 2+0$ & 14 & 14 & \\
\hline $\mathrm{P} 2+1$ & 14 & 14 & \\
\hline Total & 100 & 100 & \\
\hline \multicolumn{4}{|l|}{ Level of education } \\
\hline No formal education & 8 & 8 & \multirow{3}{*}{0.001} \\
\hline Primary education & 32 & 32 & \\
\hline Secondary education & 60 & 60 & \\
\hline
\end{tabular}


$(p=0.03)$. The majority of women had secondary school education. The remainders were illiterate or had primary school education. The result was statistically significant $(p<0.0001)$. In our study, $42(42.0 \%)$ mothers delivered by caesarean section whereas 58 (58.0\%) mothers delivered by vaginal route.

[Table/Fig-3] showed that the most common reason for acceptance of PPIUCD was its long-term effect of contraception followed by reversible nature. A total of 21 women accepted for non hormonal contraceptive and only nine mothers accepted for safety of PPIUCD. The result was statistically significant $(p<0.05)$. Refusal rate was $6 \%$. Among the women who refused, majority was due to fear of complications, followed by partner's refusal and preference to other methods and only one mother had no specific reason. Among 94 mothers, who accepted PPIUCD, only three mothers were lost to follow-up and out of 91 mothers, PPIUCD was removed in seven mothers, four mothers had spontaneously expelled and 80 mothers continued PPIUCD. Two mothers had complication and two had family pressure for the removal of PPIUCD which was statistically significant $(p<0.0001)$. Only two mothers conceived with PPIUCD in-situ.

\begin{tabular}{|c|c|c|c|}
\hline Reasons & $\begin{array}{c}\text { Numbers } \\
\text { (n) }\end{array}$ & $\begin{array}{l}\text { Percentages } \\
(\%)\end{array}$ & $\mathrm{p}$-value \\
\hline \multicolumn{4}{|l|}{ Reason for acceptance } \\
\hline Long-term contraceptive & 38 & 40.4 & \multirow{5}{*}{0.05} \\
\hline Non hormonal contraceptive & 21 & 22.3 & \\
\hline Reversible & 26 & 27.7 & \\
\hline Safe & 9 & 9.6 & \\
\hline Total number of mothers accepted PPIUCD & 94 & 100 & \\
\hline \multicolumn{4}{|l|}{ Reason for refusal } \\
\hline Partner refusal & 1 & 16.7 & \multirow{8}{*}{$<0.0001$} \\
\hline Fear of complications & 3 & 50 & \\
\hline Religious & 0 & 0 & \\
\hline Preference to another method & 1 & 16.7 & \\
\hline Fears cancer & 0 & 0 & \\
\hline No specific reason & 1 & 16.7 & \\
\hline Total no of mother refused & 6 & 100 & \\
\hline Removal of PPIUCD & 7 & 100 & \\
\hline \multicolumn{4}{|l|}{ Reason for removal } \\
\hline Complication & 2 & 28.6 & \multirow{6}{*}{0.0455} \\
\hline Family pressure & 2 & 28.6 & \\
\hline Preference to other method & 1 & 14.3 & \\
\hline Conceived with PPIUCD in-situ (Failure) & 2 & 28.6 & \\
\hline Expulsion of PPIUCD & 4 & & \\
\hline Continuation of PPIUCD & 80 & & \\
\hline
\end{tabular}

[Table/Fig-4] showed that out of 91 mothers, majority mothers (87.9\%) continued PPIUCD among them only three mothers had abdominal discomfort, 10 had abnormal bleeding PN, and 67 (90.4\%) mothers had no complications. Failure rate was $2.2 \%$. Only two mothers conceived with PPIUCD in-situ. Expulsion rate was 5.4\%.

\begin{tabular}{|l|c|c|c|c|c|}
\hline Problems & Total & $\begin{array}{c}\text { Removal } \\
\text { of PPIUCD }\end{array}$ & $\begin{array}{c}\text { Expulsion } \\
\text { of PPIUCD }\end{array}$ & $\begin{array}{c}\text { Continuation } \\
\text { with PPIUCD }\end{array}$ & p-value \\
\hline $\begin{array}{l}\text { Abdominal } \\
\text { discomfort }\end{array}$ & $5(5.5 \%)$ & $2(40 \%)$ & - & $3(60 \%)$ & 0.5287 \\
\hline $\begin{array}{l}\text { Abnormal } \\
\text { bleeding PN }\end{array}$ & $10(11 \%)$ & 0 & - & $10(100 \%)$ & $<0.0001$ \\
\hline $\begin{array}{l}\text { Conceived with } \\
\text { PPIUCD in-situ } \\
\text { (Failure rate) }\end{array}$ & $2(2.2 \%)$ & $2(2.2 \%)$ & - & - & 0.0455 \\
\hline No complication & $74(81.3 \%)$ & $3(4.05 \%)$ & $4(5.4 \%)$ & $67(90.5 \%)$ & $<0.0001$ \\
\hline Total & $91(100 \%)$ & $7(7.7 \%)$ & $4(5.4 \%)$ & $80(87.9 \%)$ & \\
\hline
\end{tabular}

\section{DISCUSSION}

In our study, conducted in a tertiary care hospital, we aimed to determine the acceptability, safety, efficacy and outcome of PPIUCD following both vaginal delivery and caesarean section. Very high rate of acceptance of about $94 \%$ was found in this study. The most common reason for acceptance was its long-term effect followed by reversible nature. Our findings were similar to some studies $[7,8]$. According to other studies, reversible nature of IUCD seems to be the most common cause for acceptance followed by longterm contraceptive property, safety and non hormonal property [9]. Whereas some studies showed safety was the primary reason for acceptance $[8,10]$. This study showed low refusal rate. Among the women who refused, majority was due to fear of complications followed by partner's refusal and preference to other methods and there was no specific reason in some cases.

Acceptance of PPIUD did appear to be related to the quality of PPIUD counselling received and educational status of mothers. All mothers were counselled by doctors. Majority of mothers had completed secondary education, followed by primary schooling and few mothers had no formal education. Education status plays an important role in motivating and preparing patient for PPIUCD use as there are many myths prevailing in country about IUCD. Fear of serious complications, infection, cancer and religious beliefs, hinders its use among mothers but educated mothers understand the advantage and have positive attitude towards its use once counseled. These findings were similar to other studies $[9,11]$. Majority of women who accepted PPIUCD were primipara mother. Most of the mother receiving PPIUCD were between 20 to 30 years age group. A study conducted in Tamil Nadu by the Directorate of Health, which showed 59\% acceptors in 20-24 group, 31\% in 2529 group, 6.5\% in 34-44 group and 4\% in the 15-19 group [12].

It was found that nonacceptance of PPIUCD was corroborated to its side-effects. Abnormal bleeding PN and abdominal discomfort being the foremost cause. Among 91 women followed-up for safety profile of PPIUCD, majority had no complication which was statistically significant. Only five mothers suffered from lower abdominal pain and ten mothers reported abnormal bleeding PN. Failure rate was $2.2 \%$. Only two mothers conceived with IUCD in situ. Kumar $S$ et al., assessed satisfaction and complications following PPIUCD insertion using standardised questionnaire [13]. Of $62.8 \%$ women continuing with the method beyond one year, 19.3\% reported removal of PPIUCD for associated bleeding PN and pain abdomen. Another study [14] reported from Sri Lanka showed that at the end of 3 months, $6.7 \%$ of women complained abdominal pain in caesarean section group and $0.8 \%$ in vaginal delivery group. Abnormal vaginal bleeding with $6 \%$ and $2.2 \%$ in caesarean section and vaginal delivery group respectively.

The current study also focused upon the outcome of PPIUCD in oneyear course under the heading of expulsion, removal and continuation of PPIUCD. We found that expulsion rate was $4.4 \%$ within 6 weeks and out of four, only one mother reported expulsion within 1 week. During follow-up visits at 12 weeks and 24 weeks, seven women requested and underwent removal of PPIUCD for varied reasons. Our finding of low expulsion rate was comparable with one study [13]. They found the rate of expulsion was 3.6\% and $7.5 \%$ by 6 weeks and one year of follow-up respectively. Other studies found low expulsion rate $[15,16]$, One study showed high expulsion rate (18\%) and removal rate (13\%) at 6 weeks postpartum [17].

\section{Limitation(s)}

In spite of every sincere effort, our study had certain limitations. Firstly, our study has been done in a single centre and carried out in a tertiary care hospital. Secondly, the sample size was small and period of follow-up was short. Further, large multicentric trials with a greater number of subjects and long-term follow-up should be carried out. 


\section{CONCLUSION(S)}

PPIUCD is widely accepted, efficacious, safe method of contraception. This method of family planning can further improve women's health and can reduce maternal morbidity and mortality.

\section{Acknowledgement}

We are thankful to the Principal, Nil Ratan Sircar Medical College and Hospital, Kolkata for allowing us to carry out the study.

\section{REFERENCES}

[1] Hooda R, Mann S, Nanda S, Gupta A, More H, Bhutani J. Immediate postpartum intrauterine contraceptive device insertions in caesarean and vaginal deliveries: A comparative study of follow-up outcomes. International Journal of Reproductive Medicine. 2016. doi.org:10.1155/2016/7695847.

[2] Family Planning Division. Ministry of Health and Family Welfare. Government of India. IUCD Reference Manual for Medical Officers and Nursing Personnel; 2013 Sept 26, Available from: http://www.nhm.gov.in /images/pdf/programmes.

[3] World Health Organization. Medical eligibility criteria for contraceptive use. Fifth edition 2015; Pp. 190. https://apps.who.int/iris/bitstream/handle/10665/18146 8/9789241549158.

[4] Subhashgadre S. Level of acceptance of IUCD insertion in Indian women a cross sectional mixed research from central India. International Journal of Reproduction and Contraception Obstet Gynecol. 2015;4(4):1079-83.

[5] Ministry of Health and Family Welfare, Government of India. National Rural Health Mission. 2018 Jun 27. http://nhm.gov.in/.

[6] Kanhere A, Pateriya P, Jain M. Acceptability and feasibility of immediate postpartum IUCD insertion in a tertiary care centre in Central India. International Journal of Reproduction, Contraception, Obstetrics and Gynecology. 2015;4(1):179-84.

[7] Bhadra B, Sougata K, Burman CN, Purandare, Divakar H, et al. The impact of using nurses to perform postpartum intrauterine device insertions in Kalyani Hospital, India. International Journal of Gynecol Obstet. 2018;143(Suppl. 1):33-37.
[8] Maluchuru S, Aruna V. Post-partum - intrauterine device insertion- $2 \mathrm{yr}$ experience at a tertiary care center in Guntur Medical College/Govt. Genera Hospital, Guntur. IOSR Journal of Dental and Medical Sciences Ver IV. 2015;14(7):2279-861.

[9] Jairaj S, Dayyala S. A cross sectional study on acceptability and safety of IUCD among postpartum mothers at tertiary care hospital, Telangana. Journal of Clinical and Diagnostic Research. 2016;10(1):LC01.

[10] Mishra S. Evaluation of safety, efficacy, and expulsion of Postplacental and IntraCesarean Insertion of Intrauterine Contraceptive Devices (PPIUCD). J Obstet Gynaecol India. 2014;64(5):337-43.

[11] Mohamed SA, Kamel MA, Shaaban OM, Salem HT. Acceptability for the use of postpartum intrauterine contraceptive devices: Assiut experience. Med Princ Pract. 2003;12:170-75

[12] PPIUCD survey findings: Dr.A.Chandranathan, Director of Family Welfare i/c, tnhealth.tn.gov.in/tngovin/dfw/notification/nov 2014

[13] Kumar S, Sethi R, Balasubramaniam S, Charurat E, Lalchandani K, Semba R, et al. Women's experience with postpartum intrauterine contraceptive device use in India. Reproductive Health. 2014;11(1):32.

[14] Rishard MR, Pushpakanthan EJ, Nishad AAN, Hewage SA, Gunawardane K. Safety and success of immediate post-placental intrauterine device insertion at the time of cesarean section. Sri Lanka Journal of Obstetrics and Gynaecology. 2017;39(2):36-37.

[15] Xess S, Sharma M, Rajoria L, Mehta S. A study to evaluate and compare the expulsion, removal and continuation of postplacental insertion of Cu 375 and CUT 380A in Indian women. International Journal of Clinical Obstetrics and Gynaecology. 2018; 2(1):33-38.

[16] Banapurmath ST, Dotrad GB, Doreswamy N, Shyamala. Feasibility of postpartum insertion of intrauterine contraceptive device-expanding the use of intrauterine contraceptive device in post-partum period-A cross sectional study in developing country. India. Int J Cur Res Rev. 2014:6(14):38-48.

[17] Kant S, Archana S, Singh AK, Ahamed F, Haldar P. Acceptance rate, probability of follow-up, and expulsion of postpartum intrauterine contraceptive device offered at two primary health centers, North India. J Family Med Prim Care. 2016;5:770-76.

PARTICULARS OF CONTRIBUTORS:

1. Associate Professor, Department of Obstetrics and Gynaecology, Nil Ratan Sircar Medical College and Hospital, Kolkata, West Bengal, India.

2. Associate Professor, Department of Obstetrics and Gynaecology, Nil Ratan Sircar Medical College and Hospital, Kolkata, West Bengal, India.

3. Ex-Professor, Department of Obstetrics and Gynaecology, Lord Buddha Koshi Medical College, Saharsa, Bihar, India.

4. $3^{\text {rd }}$ Year PGT, Department of Obstetrics and Gynaecology, Nil Ratan Sircar Medical College and Hospital, Kolkata, West Bengal, India

5. Professor, Department of Obstetrics and Gynaecology, North Bengal Medical College, Sushrutnagar, Siliguri, West Bengal, India.

NAME, ADDRESS, E-MAIL ID OF THE CORRESPONDING AUTHOR:

Subir Kumar Bhattacharyya,

FD 65/7, FD Block, Sector III, Bidhannagar, Kolkata, West Bengal, India.

E-mail: drsubir69@yahoo.com
PLAGIARISM CHECKING METHODS: [Jain Het al.]

- Plagiarism X-checker: Dec 05, 2020

- Manual Googling: Apr 02, 2021

- iThenticate Software: Feb 24, 2021 (24\%)
ETYMOLOGY: Author Origin

\section{AUTHOR DECLARATION}

- Financial or Other Competing Interests: None

- Was Ethics Committee Approval obtained for this study? Yes

- Was informed consent obtained from the subjects involved in the study? Yes

- For any images presented appropriate consent has been obtained from the subjects. NA
Date of Submission: Dec 04, 2020

Date of Peer Review: Feb 05, 2021

Date of Acceptance: Apr 03, 2021

Date of Publishing: Jul 01, 2021 